\title{
Laser test facility 'will maintain deterrence'
}

Paris. The French government has approved the construction of a 1.8-megajoule laser for nuclear weapons research as part of its plans to maintain the country's nuclear deterrent without having to carry out explosive nuclear tests of its hydrogen bombs.

The laser facility is estimated to cost FF6 billion. It is almost identical to the \$1.8-billion National Ignition Facility (NIF) planned for the Lawrence Livermore National Laboratory in California (see Nature 371, 729: 1994).

But whereas the US decision to build NIF has provoked a vigorous debate over its impact on efforts to contain the proliferation of nuclear weapons, France's decision has been overshadowed by the question of whether the election of a new president next weekend will lead to the end of its selfimposed moratorium on explosive testing.

In France, all decisions concerning the nuclear deterrent come under the direct responsibility of the president. The moratorium was introduced in 1992 by President François Mitterrand, who, in a late conversion to the cause of non-proliferation, argued that tests could only lead to an escalation of the arms race and the temptation to develop battlefield nuclear weapons.

Mitterrand claimed that France's existing nuclear deterrent is sufficient for its defence needs, and could be modernized by the year 2010 using simulation techniques rather than direct testing. But others have expressed concern that a moratorium will make it impossible to achieve the required modernization, such as increased miniaturization and an enhanced capacity of warheads to penetrate defences, as well as to guarantee their reliability. the conservative-dominated parliament concluded that France's current nuclear weapons would only be an effective deterrent until 2010. But it argued that France lagged behind other countries in simulation techniques, and needed to carry out ten explosive tests to validate its simulation methods, as well as a further ten to test upgraded weapons in the existing arsenal.

France has about 500 nuclear warheads,
In 1993, for example, a commission of

including 385 150-kilotonne intercontinental ballistic missiles (ICBMs) carried aboard submarines and 18 others housed in fixed silos on the Plateau d'Albion. It plans to modernize this arsenal, in particular by introducing the M5 ICBM for the next-generation Triumphant-class submarines and the ASLP air-to-surface missile for the Rafale aircraft.

Jacques Chirac, the Gaullist candidate in the presidential election, has taken up the parliamentary commission's conclusions,

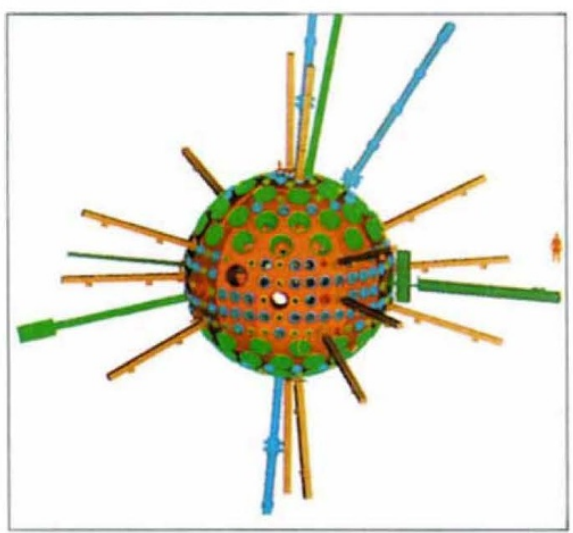

Test chamber: $\mathbf{1 . 8}$ million joules In a flash.

saying that France may need to carry out more tests, adding that it should also set a date for a definitive stop. His rival, the socialist Lionel Jospin, has called for a permanent test ban.

Whatever the outcome, the decision to build the new laser marks France's biggest step towards using computer modelling and simulation to modernize its current nuclear deterrent while reducing the need for testing in the future. It is part of the wider PALEN programme (Preparation for Limitation of Nuclear Tests), approved in 1993, on which FF900 million was spent last year.

The facility will be built at the Centre d'Etudes Scientifiques et Techniques d'Aquitaine (CESTA) in Le Barp, $30 \mathrm{~km}$ from Bordeaux. The research centre is one of the six operated by the Military Applications Division (DAM) of the CEA. The machine will be built between 1996 to 2002

\section{Chinese students abroad face cash deposit}

London. The Chinese government has increased efforts to slow down its brain drain by insisting that students intending to study abroad on government scholarships place a cash deposit worth half the scholarship before they depart. The money will be refunded only when they return.

The move was reported last week in the Beijing newspaper Youth Daily. Of an estimated 200,000 students to have left China since the start of the 1980 s to study abroad, just 70,000 have returned.
In addition to the cash deposit, the government, according to the report, will insist on recording the names and addresses of two 'guarantors' for each student who will be traced and questioned should the student decide not to come back to China.

Previous measures taken by the Beijing government to dissuade students from overstaying abroad include insisting families of married students remain in China and asking European and US interior ministries to refuse work permits. and, according to Daniel Wisshaupt, the manager of the programme, will reach full power by 2005 .

The main laser will be 60 metres high and will cover the area of two football fields. A labyrinth of mirrors will reflect light from 240 lasers into a spherical test chamber, 10 metres in diameter. This will contain at its centre a supercold pellet, a few millimetres in diameter, of deuterium and tritium, two isotopes of hydrogen.

During a flash lasting a few nanoseconds, the lasers will unleash 500 terawatts on to the walls of the chamber. This will create a barrage of X-rays that will compress the pellet, heat it to 100 million degrees, and trigger a process of sustained thermonuclear fusion that will increase the temperature to 400 million degrees.

The physical conditions, such as temperature, density and pressure, produced by this miniature thermonuclear explosion will be similar to those in an exploding hydrogen bomb, allowing study of implosion, the acceleration of particles and absorption and emission patterns of nuclear radiation.

Although the energy represents several hundred-thousand times the output of a conventional nuclear reactor, the lights on the Champs-Elysées will not dim each time the laser is fired. As in a camera flash, the energy would be stored up and then released over a very brief period. Indeed, while the power of 1.8 million joules is enormous for a laser, it is comparable to the energy content of a 12-volt car battery.

But if the physics is relatively straightforward, the politics are not. Both the US and French decisions to build such lasers have been interpreted by some as evidence that the two countries want to circumvent a test ban. Steven Dolley, for example, research director at the Nuclear Control Center in Washington, disputes US claims that simulation is needed to improve the safety and reliability of weapons. Dolley argues that such issues have nothing to do with nucleonics, but involve the conventional high-explosive part of the weapons. Lasers, he claims, could be used to design new weapons, and increase the risk of proliferation.

A senior official at DAM agrees that the ban has made it "necessary to rethink everything". But he argues that building the laser will not encourage proliferation, as only states that have already carried out tests will be able to benefit from the simulations.

Although the new laser will also provide physicists with a new toy for studying how stars shine, he says its is unlikely that France will investigate the laser as a means of harnessing thermonuclear power for electricity production. It has committed itself to the magnetic confinement techniques used in tokamaks, and cannot afford to pursue laser experiments in parallel.

Declan Butler 